\title{
THE RELATIONSHIP OF MIGRAINE WITH SMARTPHONE USE
}

\author{
Levent Şahin $\odot$, Turgut Dolanbay® \\ Department of Emergency Medicine, Kafkas University Health Research and Application Hospital, Kars, Turkey
}

\begin{abstract}
INTRODUCTION: It was aimed to determine the existence of a relationship between smartphone use and the severity and frequency of attacks of migraine in patients diagnosed with migraine who were admitted to the emergency department of a university hospital with the complaint of headache by using the survey method.

MATERIAL AND METHODS: Migraine patients who came to the emergency department with headache in the last 1 year, were retrospectively analyzed. Afterwards, 119 patients who were readmitted within 3 months from this patient group were included in the survey study. All patients were asked about their preferences for smartphone use, duration of phone use, and whether they had received migraine treatment previously. The severity of pain was determined according to the visual analog scale.
\end{abstract}

RESULTS: The migraine attacks of 38 patients with drug use were observed 7.65 times on average in a year. In the group without drug use, they were observed 9.80 times on average in a year. While the number of patients, who preferred talking as a preference for smartphone use, was $35(29.4 \%), 7(5.8 \%)$ patients preferred messaging, $10(8.4 \%)$ patients preferred playing games, and $67(56.3 \%)$ patients preferred surfing social media - the internet. No significant relationship was found between the severity of migraine pain and the preference for phone use $(p=0.08)$ (Tab.2).

CONCLUSIONS: There is a need for more comprehensive experimental and epidemiological studies to confirm the relationship between migraine severity and the devices with high-frequency electromagnetic areas such as smartphones.

KEY WORDS: migraine, smartphone, electromagnetic areas

Disaster Emerg Med J 2020; 5(4)

\section{INTRODUCTION}

Headache is a symptom that is one of the most common complaints in the world and occurs for various reasons. Primary headaches (tension-type headache, cluster-type headache, and migraine) constitute the majority of patients presenting with headache [1]. Migraine is an episodic headache type accompanied by neurological, gastrointestinal, and autonomic changes. It is a significant health problem, which is the second most common in primary headaches, affects approximately more than $10 \%$ of the general population, and impairs the quality of life [2]. Since migraine attacks may last for hours and sometimes for days, it leads to the restriction of daily activities of people [3].

The use of smartphones and computers has increased significantly since the 1990s, especially in recent years around the world [4]. Along with the fact that smartphones have become lighter with each passing day, they have become easy to carry and have surpassed computer use. Since these phones have many features such as messaging, camera, 
game, access to the internet and social networks, videos, multimedia and navigation, they cause more time to be spent during the day. As a result of limited studies, it was reported that smartphone users had mild side effects such as headache, sleep disorder, attention deficit, short-term memory loss, dizziness, tinnitus, and chronic fatigue [5]. The use of smartphones has been increasing significantly, especially among young people. On the other hand, complaints of headache are increasing around the world. However, the causal relationship between phone use and headache has not been fully explained yet [6]. It was observed that the survey studies discussing the relationship between the severity and frequency of attacks of migraine and smartphone use were not sufficient. In our study, it was aimed to determine the existence of a relationship between the daily duration of smartphone use and the severity and frequency of attacks of migraine in patients diagnosed with migraine, who were admitted to the emergency department, by using the survey method.

\section{MATERIALS AND METHODS}

Approval for the study was obtained from the Ethics Committee of Kafkas University, Faculty of Medicine (Ethics committee date: 30.10.2019, Decision Number: 80576354-050-99/237). Three hundred thirty-seven patients diagnosed with migraine according to the ICD diagnosis code, who had been admitted to our hospital's emergency department with headache in the last 1 year, were retrospectively examined. It was planned to conduct a voluntary survey when these patients would be admitted to our emergency department again. Among 337 patients with a diagnosis of migraine, 135 patients who were admitted to the emergency department for the second time between 01.11.2019-01.02.2020 were included in the survey study. Information about the study was provided, 9 people refused to participate in the study, and 7 people were excluded from the study since they used classic phones. The survey study was conducted with the remaining 119 patients. In the form, participants were asked about their first preference for smartphone use, daily duration of phone use, educational status, and whether they had received migraine treatment previously. The pain severity of patients was evaluated by the Visual Analog Scale (VAS) because of its quick and simple scoring. Indi- viduals were told that they could evaluate their pain from 0 to 10 on a $10 \mathrm{~cm}$ line, the place marked by the individual on the chart was measured with a ruler, and the value found was written as the severity of pain $[7,8]$. It was considered that the patients with a VAS score of $30 \mathrm{~mm}$ or less had mild pain, those with a VAS score of $70 \mathrm{~mm}$ or more had severe pain, and those with a VAS score of over $30 \mathrm{~mm}$ and below $70 \mathrm{~mm}$ had moderate pain [9]. In this study, it was aimed to determine the relationship between the exposure to smartphone use and migraine attack and severity. The patients were examined for the duration of migraine (in years), the frequency of attacks (the number of attacks experienced in 1 year), the duration of attacks (how many hours they last), educational status, drug use status, and pain severity.

\section{Statistical analysis}

The demographic data of the patients were determined by statistical analyses. The Pearson chi-square test was performed between the groups determined. The data obtained were statistically analyzed using the IBM SPSS 20 program. $P<0.05$ was considered significant for all statistical data.

\section{RESULTS}

One hundred nineteen patients diagnosed with migraine who were included in the study consisted of 53 males and 66 females. The average age of the patients was $33.34 \pm 11.35$ (min. age $=19$, max. age $=69$ ). In our study, it was observed that smartphone users' daily duration of time spent on the phone was maximum 8 hours and minimum 1 hour. The average period of migraine attacks of $119 \mathrm{pa}$ tients was observed to be approximately 12 times a year. It was found that the frequency of migraine attacks was less frequently observed among those with drug use compared to those without drug use. While the average of migraine attacks of 38 patients with drug use was 7.65 times on average in a year, it was observed to be 9.80 times in a year in the group without drug use.

According to educational status, while 5 of those with drug use were primary and secondary education graduates, 11 of them were high school graduates, 19 of them were university graduates, and 3 of them had a master's degree. While 13 of those without drug use were primary and secondary education graduates, 14 of them were high school 
graduates, 45 of them were university graduates, and 9 of them had a master's degree (Tab. 1).

In migraine patients who were asked about their preferences for smartphone use, while 35 people used it for talking purposes, 10 people used it for gaming purposes, 67 used it for surfing social media and the internet, and 7 people used it for messaging purposes. The frequency of migraine attacks was observed to be 8.73 times on average in a year in individuals who spent time on the phone primarily for surfing the internet and social media. Migraine attacks were observed 8.28 times on average in a year in those who used it for messaging purposes, they were observed 9.11 times on average in a year in those who used it for talking purposes, and they were observed 12.4 times on average in a year in those who used it for gaming purposes (Tab. 2).

According to the VAS, the patients were classified separately as those with regular drug use and those without drug use. These two groups were examined under three groups as mild, moderate, and severe according to the severity of pain (Tab. 3).

As a result of the chi-square test, no significant relationship was found between the severity of migraine pain and the duration of phone use $(p=0.18)$ No significant relationship was found between the severity of migraine pain and the preference for phone use $(p=0.08)$. A significant relationship was found between the severity of migraine pain and the number of migraine attacks per year. Accordingly, there was a relative increase between moderate pain observed 2-4 times a year according to the VAS and severe pain observed 6-12 times a year according to the VAS $(p<0.05)(p=0.01)$. It was observed that no significant relationship was found between the severity of migraine pain and gender $(p=0.57)$.

\section{DISCUSSION}

Migraine, a common type of headache, affects approximately $12 \%$ of the population, mostly young and middle-aged individuals around the world [10]. Migraine is more common in women than men in society. When the studies were considered, it was observed that the prevalence of migraine was found to be two times higher in women compared to men in the general population [11]. When age groups were examined, it appeared that the prevalence of migraine peaked in the $3^{\text {rd }}$ decade in women; however, it was observed at the highest level in the $4^{\text {th }}$

Table 1. Relationship between the level of
education and drug use
\begin{tabular}{|l|c|c|}
\hline \multicolumn{1}{|c|}{ Educational status } & $\begin{array}{c}\text { Those with } \\
\text { drug use }\end{array}$ & $\begin{array}{c}\text { Those without } \\
\text { drug use }\end{array}$ \\
\hline $\begin{array}{l}\text { Primary and secondary } \\
\text { education }\end{array}$ & $5(13.1 \%)$ & $13(16 \%)$ \\
\hline High school & $11(28.9 \%)$ & $14(17.2 \%)$ \\
\hline University & $19(50 \%)$ & $45(55.5 \%)$ \\
\hline $\begin{array}{l}\text { Master's and doctorate } \\
\text { degrees }\end{array}$ & $3(7.9 \%)$ & $9(11.1 \%)$ \\
\hline
\end{tabular}

Table 2. Relationship between preferences for phone use and the frequency of migraine attacks

\begin{tabular}{|l|c|c|}
\hline Preference for use & $\begin{array}{c}\text { Number of } \\
\text { people }\end{array}$ & $\begin{array}{c}\text { Number of } \\
\text { migraine attacks }\end{array}$ \\
\hline Talking & $35(29.4 \%)$ & $9.11(23.6 \%)$ \\
\hline Messaging & $7(5.8 \%)$ & $8.28(21.5 \%)$ \\
\hline Playing games & $10(8.4 \%)$ & $12.40(32.2 \%)$ \\
\hline $\begin{array}{l}\text { Social media } \\
\text { Surfing the Internet }\end{array}$ & $67(56.3 \%)$ & $8.73(22.6 \%)$ \\
\hline
\end{tabular}

Table 3. Relationship between drug use and Visual Analog Scale

\begin{tabular}{|l|c|c|}
\hline VAS severity & $\begin{array}{c}\text { Those with drug } \\
\text { use }\end{array}$ & $\begin{array}{c}\text { Those without drug } \\
\text { ufse }\end{array}$ \\
\hline Mild & $5(13.1 \%)$ & $13(16.1 \%)$ \\
\hline Moderate & $13(34.2 \%)$ & $42(51.8 \%)$ \\
\hline Severe & $20(52.7 \%)$ & $26(32.1 \%)$ \\
\hline
\end{tabular}

VAS - Visual Analog Scale

decade in men [12]. Preventive treatment should be administered for all patients with chronic migraine. However, in the studies conducted, it was observed that only $3-13 \%$ of the patients used prophylactic drugs [13]. In our study, a high rate of drug use was found by $32 \%$. We considered that it was due to easy access to the physician because of the small size of the city we were in and a good health literacy level of patients.

When the frequency of attacks was examined, playing games was the most common reason for attacks by $12.40 \%$, we found that the preference for talking on the phone was the second most common reason for attacks by $9.11 \%$, and smartphone users' daily duration of the time spent on the phone was 4 hours 33 minutes. In the study carried out by Kucer $\mathrm{N}$ and Pamukcu $\mathrm{T}$, the group with a daily duration 
of cell phone usage of $>16$ minutes (min) was compared with the group with a daily duration of cell phone usage of $<16$ minutes. It was reported that there were significant increases in headache, hearing loss, and joint and bone pain in people with a duration of cell phone usage of $>16$ minutes [14].

Our body has a weak electromagnetic area (EMA) since it consists of water, ions, and electrolytes by $70 \%$. We are exposed to EMAs, mostly due to power lines, computers, televisions, radios, and phones [15]. The frequency ranges of mobile phones are between $10 \mathrm{MHz}-3000 \mathrm{GHz}$, and they have hyper frequency EMAs [16]. These mobile phones with powerful frequency may have destructive effects on tissues containing high concentrations of electrons and ions. In the studies, it was observed that EMA had some effects on cell behaviors, such as changing the function of the cardiovascular system and bone marrow $[17,18]$. There are different studies revealing that EMAs caused by phones had significant side effects such as headache, decreased memory performance, impaired sleep and quality of life, attention and concentration impairment [19-21].

Insomnia, hormonal changes, fasting, alcohol intake, certain foods, weather condition, light, and noise, which are among the triggering factors, increase the frequency of migraine attacks. Although we know the presence of many factors which are considered to trigger migraine attacks, how migraine pain begins, in which region of the brain it begins, which regions of the brain are active in the stages of a migraine, and what kind of relationship there is between these triggering factors and migraine are among the issues that have not been clarified yet $[22,23]$. Although there are few studies on determining these triggering causes, they have gained speed recently. There are scientific studies especially about the effect of electromagnetic waves emitted by mobile phones on human health [24]. The excessive use of smartphones is estimated to cause some organic and psychological health problems. In the studies conducted, it was reported that many people had problems such as eye fatigue, burning eyes, eye redness, eye dryness, blurred vision, neck pain, decreased proprioception, posture disorder, anxiety, depression, and headache after the long-term use of smartphones $[25,26]$. In accordance with a similar study on this subject, it was demonstrated that excessive smartphone use increased migraine headache [27]. In this study, no significant relationship was found between the severity of migraine pain and preferences for smartphone use (talking on the phone, messaging on the phone, playing games on the phone, and using the Internet - social media) $(p=0.08)$. However, the group playing games on the phone had the highest percentage of migraine attacks by $32.2 \%$. We considered that it was due to the fact that focusing on the constantly changing colored light on the screen for a long time while playing games could be a triggering factor that could increase the frequency of attacks.

Unlike other headaches, migraine headache increases with light. Various studies have been carried out on it using electrophysiological tests. It was demonstrated that white, blue, and red lights increased migraine headaches more than other color lights [28]. In the study carried out by Park JM et al., it was found that the excessive use of smartphones could be a triggering factor for migraine attacks since it would always expose patients to light [29].

In our survey study carried out to find out the relationship between smartphone use and the severity and frequency of attacks of migraine, we found no relationship. When we consider the results of our study, we estimate that smartphones may have adverse effects on the human brain. We can predict that the prevalence of digital screen exposure will be even higher along with the advancement of technology in the future. The investigation of triggering factors will help us to understand the pathophysiology of migraine more clearly and to develop a preventive strategy for these triggering factors. There is a need for comprehensive experimental and epidemiological studies to investigate the effects of devices with high-frequency EMAs on human health.

\section{Limitations}

Nevertheless, there are some limitations to our current study. The city where our hospital is located has a low population. It was less than expected for patients to participate in the survey study and hence a multicenter study with a large number of patients is needed.

\section{CONCLUSIONS}

We recommend that the long-term use of smartphones, which is considered to be among the causes of migraine and migraine attacks, should be avoided. Furthermore, it is necessary to raise the awareness of people with headaches in society regarding 
the harmful effects of smartphone exposure on migraine.

Acknowledgements: The authors would like to thank neurology physician Can Emre Erdoğan for neurology counseling.

Statement of competing interests: There is no conflict of interest competing among the authors.

\section{REFERENCES}

1. Frishberg BM, Rosenberg J, Matchar D, et al. Evidence Based Guidelines in the Primary Care Setting: Neuroimaging in Patients with Nonacute Headache. St Paul, MN: US Headache Consortium. ; 2000: 1-25.

2. Barbanti $P$, Aurilia $C$, Egeo $G$, et al. Migraine prophylaxis: what is new and what we need? Neurol Sci. 2011; 32 Suppl 1: S111-S115, doi: 10.1007/s10072-011-0526-3, indexed in Pubmed: 21533725.

3. Bigal ME, Rapoport AM, Lipton RB, et al. Assessment of migraine disability using the migraine disability assessment (MIDAS) questionnaire: a comparison of chronic migraine with episodic migraine. Headache. 2003; 43(4): 336-342, doi: 10.1046/j.1526-4610.2003.03068.x, indexed in Pubmed: 12656704.

4. Röösli M, Frei P, Mohler E, et al. Systematic review on the health effects of exposure to radiofrequency electromagnetic fields from mobile phone base stations. Bull World Health Organ. 2010; 88(12): 887896F, doi: 10.2471/BLT.09.071852, indexed in Pubmed: 21124713.

5. Röösli M, Moser M, Baldinini Y, et al. Symptoms of ill health ascribed to electromagnetic field exposure--a questionnaire survey. Int J Hyg Environ Health. 2004; 207(2): 141-150, doi: 10.1078/1438-463900269, indexed in Pubmed: 15031956.

6. Chu MK, Song HG, Kim C, et al. Clinical features of headache associated with mobile phone use: a cross-sectional study in university students. BMC Neurol. 2011; 11: 115, doi: 10.1186/1471-2377-11-115, indexed in Pubmed: 21943309.

7. Clark $P$, Lavielle $P$, Martínez H. Learning from pain scales: patient perspective. J Rheumatol. 2003; 30(7): 1584-1588, indexed in Pubmed: 12858463.

8. Hawker $\mathrm{G}$, Mian $\mathrm{S}$, Kendzerska $\mathrm{T}$, et al. Measures of adult pain: Visual Analog Scale for Pain (VAS Pain), Numeric Rating Scale for Pain (NRS Pain), McGill Pain Questionnaire (MPQ), Short-Form McGill Pain Questionnaire (SF-MPQ), Chronic Pain Grade Scale (CPGS), Short Form-36 Bodily Pain Scale (SF. Arthritis Care \& Research. 2011; 63(S11): S240-S252, doi: 10.1002/acr.20543.

9. Collins S, Moore A, McQuay H. The visual analogue pain intensity scale: what is moderate pain in millimetres? Pain. 1997; 72(1): 95-97, doi: 10.1016/50304-3959(97)00005-5.

10. Rasmussen BK. Epidemiology of headache. Cephalalgia. 2001; 21(7): 774-777, doi: 10.1177/033310240102100708, indexed in Pubmed: 11595011.

11. Ertas M, Baykan B, Orhan EK, et al. One-year prevalence and the impact of migraine and tension-type headache in Turkey: a nationwide home-based study in adults. J Headache Pain. 2012; 13(2): 147-157, doi: 10.1007/s10194-011-0414-5, indexed in Pubmed: 22246025.

12. Song TJ, Cho SJ, Kim WJ, et al. Poor sleep quality in migraine and probable migraine: a population study. J Headache Pain. 2018; 19(1): 58, doi: 10.1186/s10194-018-0887-6, indexed in Pubmed: 30046921.

13. Bigal ME, Serrano D, Buse $D$, et al. Acute migraine medications and evolution from episodic to chronic migraine: a longitudinal population-based study. Headache. 2008; 48(8): 1157-1168, doi: 10.1111/j.1526-4610.2008.01217.x, indexed in Pubmed: 18808500 .

14. Küçer N, Pamukçu T. Self-reported symptoms associated with exposure to electromagnetic fields: a questionnaire study. Electromagn Biol Med. 2014; 33(1): 15-17, doi: 10.3109/15368378.2013.783847, indexed in Pubmed: 23730819.

15. Asghari A, Khaki AA, Rajabzadeh A, et al. A review on Electromagnetic fields (EMFs) and the reproductive system. Electron Physician. 2016; 8(7): 2655-2662, doi: 10.19082/2655, indexed in Pubmed: 27648194.

16. Gye MC, Park CJ. Effect of electromagnetic field exposure on the reproductive system. Clin Exp Reprod Med. 2012; 39(1): 1-9, doi: 10.5653/cerm.2012.39.1.1, indexed in Pubmed: 22563544.

17. Daşdag`S, Akdag` M, Ayyldiz O, et al. DO CELLULAR PHONES ALTER BLOOD PARAMETERS AND BIRTH WEIGHT OF RATS? Electro- and Magnetobiology. 2009; 19(1): 107-113, doi: 10.1081/jbc-100100301.

18. Stuchly MA. Health effects of exposure to electromagnetic fields. 1995 IEEE Aerospace Applications Conference. Proceedings. , doi: 10.1109/ aero.1995.468891.

19. Al-Khamees NA. study in Kuwait of health risks associated with using cell phones. Coll Stud J. 2007; 41: 187-202.

20. Hillert L, Akerstedt $T$, Lowden A, et al. The effects of $884 \mathrm{MHz}$ GSM wireless communication signals on headache and other symptoms: an experimental provocation study. Bioelectromagnetics. 2008; 29(3): 185-196, doi: 10.1002/bem.20379, indexed in Pubmed: 18044740.

21. Demir YY, Sumer MM. Effects of smartphone overuse on headache, sleep and quality of life in migraine patients. Neurosciences (Riyadh). 2019; 24(2): 115-121, doi: 10.17712/nsj.2019.2.20180037, indexed in Pubmed: 31056543.

22. Burstein R, Noseda R, Borsook D. Migraine: multiple processes, complex pathophysiology. J Neurosci. 2015; 35(17): 6619-6629, doi: 10.1523/JNEUROSCI.0373-15.2015, indexed in Pubmed: 25926442.

23. Siniatchkin M, Averkina N, Gerber WD. Relationship between precipitating agents and neurophysiological abnormalities in migraine. Cephalalgia. 2006; 26(4): 457-465, doi: 10.1111/j.14682982.2006.01061.x, indexed in Pubmed: 16556248.

24. Mat $D$, Kho $F$, Joseph $A$, et al. Electromagnetic radiation from mobile phone near ear-skull region. International Conference on Computer and Communication Engineering (ICCCE'10). 2010, doi: 10.1109/ iccce.2010.5556752.

25. KESKIN T, ERGAN M, BAŞKURT F, et al. ÜNIVERSiTE ÖĞRENCiLERINDE AKILLI TELEFON KULLANIMI VE BAŞ AĞRISI ILIŞKKISi. Adıyaman Üniversitesi Sağlık Bilimleri Dergisi. 2018: 864-873, doi: 10.30569/ adiyamansaglik.428223. 
26. Lemola S, Perkinson-Gloor N, Brand S, et al. Adolescents' electronic media use at night, sleep disturbance, and depressive symptoms in the smartphone age. J Youth Adolesc. 2015; 44(2): 405-418, doi: 10.1007/s10964-014-0176-x, indexed in Pubmed: 25204836.

27. Cerutti R, Presaghi F, Spensieri V, et al. The Potential Impact of Internet and Mobile Use on Headache and Other Somatic Symptoms in Adolescence. A Population-Based Cross-Sectional Study. Headache. 2016; 56(7): 1161-1170, doi: 10.1111/head.12840, indexed in Pubmed: 27255862.
28. Noseda R, Bernstein CA, Nir RR, et al. Migraine photophobia originating in cone-driven retinal pathways. Brain. 2016; 139(Pt 7): 19711986, doi: 10.1093/brain/aww119, indexed in Pubmed: 27190022.

29. Park JW, Chu MK, Kim JM, et al. Analysis of Trigger Factors in Episodic Migraineurs Using a Smartphone Headache Diary Applications. PLoS One. 2016; 11(2): e0149577, doi: 10.1371/journal.pone.0149577, indexed in Pubmed: 26901341. 